\title{
Brachial plexus injury - from double to triple FFMT
}

Yuan-Kun Tu

From 10th Congress of the Asia-Pacific Federation of Societies of Surgery fo the Hand and the 6th Congress of Asia-Pacific Federation of Societies of Hand Therapists

Kuala Lumpur, Malaysia. 2-4 October 2014

\section{Introduction}

The concept of double free functioning muscle transfer (DFFMT) reconstruction for total arm type brachial plexus injury (BPI) had been successfully reported by Professor Doi from Japan. However, to overcome the weakness of finger/wrist extension after serving two functions by one gracilis muscle as described by Doi, we invented a new method of triple FFMT. This study was aimed to evaluate the clinical effectiveness of triple FFMT for total arm type BPI reconstruction.

\section{Methods}

From 2001 to 2010, 85 patients received FFMT for total arm type BPI. Five patients were excluded from this study due to inadequate vascular pattern (type B2) for DFFMT. Therefore, we had total 80 patients received the $1^{\text {st }}$ stage free gracilis-adductor DFFMT and the $2^{\text {nd }}$ stage single gracilis FFMT; so called "Triple FFMT"; for complete total avulsion BPI. There were 70 males and 10 females. The average age was 33.5 years old. The shoulder function was reconstructed by neurotization.

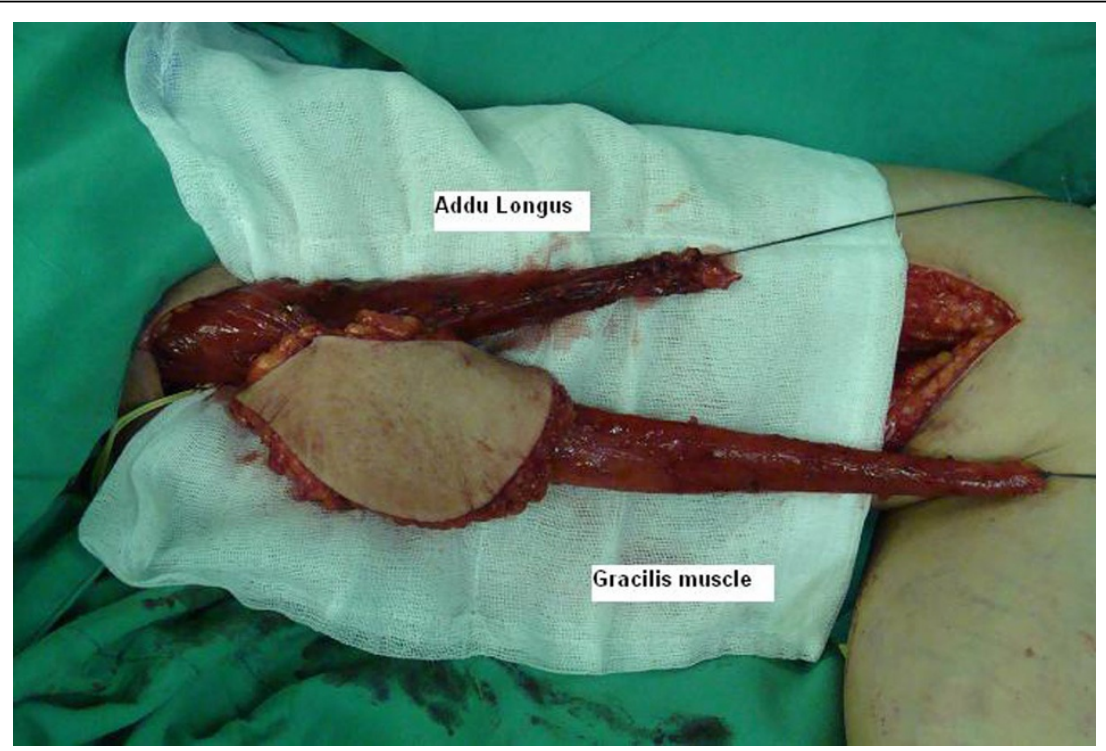

Figure 1 The combined Adductor longus-Gracilis FFMT

E-Da Hospital, Kaohsiung, 82445 Taiwan

(c) 2015 Tu; licensee BioMed Central Ltd. This is an Open Access article distributed under the terms of the Creative Commons

Attribution License (http://creativecommons.org/licenses/by/4.0), which permits unrestricted use, distribution, and reproduction in any medium, provided the original work is properly cited. The Creative Commons Public Domain Dedication waiver (http:// creativecommons.org/publicdomain/zero/1.0/) applies to the data made available in this article, unless otherwise stated. 
The $1^{\text {st }}$ DFFMT reconstructive procedures were performed in an average 3.5 months (from 2 months to 6 months) after trauma. The $2^{\text {nd }}$ gracilis FFMT was performed in an average 3 months (2 to 4.5 months) after the $1^{\text {st }}$ FFMT surgery. The $1^{\text {st }}$ DFFMT was serving as elbow flexor and finger/wrist extensor, while the second gracilis FFMT was serving as finger flexor in the $2^{\text {nd }}$ stage surgery. The average follow up was 7.5 years.

\section{Results}

The primary flap success rate (including $1^{\text {st }} \& 2^{\text {nd }}$ stage surgeries) was $97.5 \%$ (156/160 flaps), with 4 cases requiring reopen surgery due to venous thrombosis. $87.5 \%(70 / 80)$ achieved M3 elbow flexion and M3 finger/wrist extension, and 65\% (52/80) obtained M3 hand grip in 1 year follow up. In 3 years follow up, $90 \%(72 / 80)$ could have M4 elbow function and M4 finger/wrist extension, but only $70 \%$ (56/80) had M4 hand grip. The reasons for failure are: flap re-open, use of previously used nerve, tendon adhesion, lack of adequate rehabilitation, and inadequate skin coverage. The most significant recovery of motor function happened during the 9 months to 24 months after the triple FFMT surgery.

\section{Conclusion}

We concluded that triple FFMT for reconstruction of total avulsion type BPI is a worthwhile technique. This technique could offer better finger/wrist extension function than DFFMT, by adding one more FFMT in the $1^{\text {st }}$ stage surgery.

Published: 19 May 2015

doi:10.1186/1753-6561-9-S3-A29

Cite this article as: Tu: Brachial plexus injury - from double to

triple FFMT. BMC Proceedings 2015 9(Suppl 3):A29. 